\title{
Research on the Impact of Food Safety Crisis on Brand Trust: The Moderating Effect of Psychological Risk
}

\author{
Xu Zu ${ }^{1}{ }^{*}$, Weiping Yu ${ }^{2}$, Yue Qiu ${ }^{3}$ \\ ${ }^{1}$ Business School, Si Chuan Agricultural University, Chengdu, 611830; \\ ${ }^{2}$ Business School, Si Chuan University, Chengdu, 610065 \\ ${ }^{3}$ Graduate School, Chengdu University of TCM, Chengdu, 611137
}

Keywords: Food safety crisis; psychological risk; brand trust

\begin{abstract}
This paper introduces psychological risk to explore the negative impact of different categories of food safety crisis on consumer brand trust. Studies have shown that: (1) Compared with negligence, deliberate food safety crisis often has a greater negative impact on consumer brand trust. (2) Psychological risk plays a full intermediary role in the process of trustworthy and deliberate food safety crisis impact ability, and plays a role in mediating the process of affecting good faith trust. The conclusions of the study provide theoretical basis and practical reference for the follow-up crisis management strategy of food enterprises.
\end{abstract}

\section{Introduction}

Under the mobile Internet, negative events involving corporate ethics or productivity, such as "fake meat", "carrion door", "black sesame paste exceeded the standard" and the "lean meat" that came back in 2017, have evolved through extensive exposure and attention. The agricultural food safety crisis has occurred frequently, which makes consumers lack trust in the overall situation of food safety, and the trust index is only 15\%. The reputation and benefits of the same food industry will be negatively affected by the low level of brand trust. The advancement of technology in the food industry is more likely to create information asymmetry in the food market, making it more difficult for consumers to assess the psychological risks of food safety. This paper introduces consumer psychological risk and specifically explores the impact mechanism of different types of food safety crisis on consumer brand trust, and provides corresponding decision-making suggestions for marketing managers to manage food safety crisis.

\section{Literature review and research hypothesis}

\subsection{Definition and classification of food safety crisis}

The food safety crisis is subordinated to the product injury crisis, with attributes that occasionally appear and are widely publicized, which may or may be dangerous to consumers, in order to clarify the food safety crisis of enterprises, the concept of food safety crisis It is further defined as: occasional foods that contain threats (or potential threats) to consumers' health toxic or hazardous substances, or quality problems such as substandard nutrition, have been widely exposed and concerned and have (or may) be brought to enterprises or society. Events that have a huge negative impact.

Based on the perspective of attribution theory, the classification criteria of food safety crisis can be divided into three types: victim type, fault type and deliberate type. [This paper combines Zhou Yingheng and Wang Erpeng (2013) to classify the causes of modern food safety crisis as ignorance and unscrupulous. Two categories, as well as comprehensive consideration of consumer-induced cognitive attributions to the food safety crisis, eliminating the victimized categories of companies that have almost no problem responsibility due to product tampering, natural disasters, and lies, specifically exploring negligence and the impact of deliberate two types of food safety crisis on consumer brand trust. 


\subsection{Brand trust}

Combined with the Chinese research situation, Yuan Denghua et al. (2007) designed the brand trust scale to divide brand trust into three dimensions: quality trust, ability trust and good faith trust. Among them, quality trust is trust in brand quality, and ability trust is on brand. The trust of fulfilling the ability to commit, the trust of good faith is the trust that the brand will further improve the product and solve the problem. This paper believes that the product quality is still reflected in the production capacity of the enterprise. Therefore, the quality trust is merged into one dimension of competence trust, will mainly adopt the division criteria of the two dimensions of brand competence and good faith trust.

\subsection{Research hypothesis}

\subsubsection{Analysis of the main effects of two types of food safety crisis}

Since the deliberate food safety crisis involves business ethics, and the deliberate food safety crisis has a negative impact on the company's brand equity, trust can be transferred from the evidence source trusted by the credit card based on the transfer mechanism, and combined Lenovo theory, this study further speculates that compared with the negligent food safety crisis, the deliberate food safety crisis makes the consumer's good faith trust more negative, and based on the ripple effect, the deliberate food safety crisis makes the consumer's ability and trust more negative. The following assumptions are made:

H1: Deliberate food safety crisis has a negative impact on consumer brand trust than negligent food safety crisis

H1a: The deliberate food safety crisis has a negative impact on the consumer's ability to trust than the negligent food safety crisis.

H1b: Deliberate food safety crisis has a negative impact on consumers' goodwill trust than the negligent food safety crisis

\subsubsection{The mediating role of psychological risk}

The food safety crisis will make consumers feel perceived risk, the existence of consumer trust depends on perceived risk, Corbitt, Thanasankit and Yi (2003) found in the B2C platform consumer trust research that consumers' shopping experience and risk perception will affect Consumer brand trust. Stone \& Grønhaug (1993) found that physical, social, performance, and time risk changes are related to individual psychology and affect overall risk perception through psychological risk. Accordingly, this study proposes the following assumptions:

H2: Under the food safety crisis, psychological risks will negatively affect consumer brand trust.

H2a: The greater the psychological risk, the more negative the consumer's ability to trust

H2b: The greater the psychological risk, the more negative the consumer's good faith trust

The food safety crisis as a negative exposure event will bring many negative effects to the focus brand, including increasing consumer perceived risk, reducing consumer trust and so on. Fombrun \& Riel (1997) found that psychological risk is an important intermediate variable and a bridge to effectively link other categories of risk to overall risk. Based on this, this study speculates that psychological risk also acts as a mediator of the food safety crisis affecting the consumer brand trust process, and proposes the following assumptions:

H3: Psychological risk plays a mediating role in the process of food safety crisis affecting consumer brand trust

H3a: Psychological risk plays a mediating role in the process of food safety crisis affecting consumer ability and trust

H3b: Psychological risk plays a mediating role in the process of food safety crisis affecting consumers' trust in trust 


\section{Research design}

\subsection{Selected by the sample}

In this paper, college students with higher homogeneity are selected as experimental specimens for the following reasons: The first is to avoid interference with the experimental results by the individual characteristics of the sample. The second is that the campus population is highly sensitive and easy to accept new things, and is the backbone and guiding force of future market consumption. The third is that the selected samples in the research situation such as product injury crisis or negative spillover are mostly student groups, thus maintaining the inheritance of related research.

\subsection{Stimulus design}

\subsubsection{Category, brand selection}

This article chooses juice drinks as a category of food safety crisis stimuli. At the same time, it is based on the representative Huiyuan juice. Combine the news reports of Huiyuan Juice with a number of networks to modify the stimulus materials of the corporate brand profile to control the brand reputation of the juice beverage enterprise, and replace the Huiyuan juice brand name with the virtual A brand, eliminating obvious characteristic information and avoiding the reputation of consumers. Perceive differences and ultimately interfere with experimental results.

\subsubsection{Experimental material design}

Based on the news reports of several networks, the two major juice giants such as the "chlorinated door" incident in April 2012 and the "great fruit door" incidents such as Huiyuan in September 2013 were modified into two types: negligence and deliberate. The food safety crisis stimulates materials, and refers to the template of the crisis scandals by Xu Xiaolong and Su Yong (2015). The two types of crisis scandals have similar word counts.

\subsection{Variable measurement}

The measurement scales for psychological risk and brand trust (capability trust and good faith trust) are either used or modified in previous studies. The measurement of psychological risk is mainly based on the research of Stone \& Grønhaug (1993) and Founder et al. (2011). The measurement of brand (ability and goodwill) trust is mainly based on Yuan Denghua et al. (2007) and the brand trust scale of China's scenario design.

The variables that are experimentally manipulated by the sample are the brand reputation and the severity of the crisis. Ensure that the testee's brand reputation is similar to the company and avoid interfering with the experimental results. Refer to Chaudhuri (2002) and Li Guofeng (2008) and the brand characteristics of the beverage industry to design the brand reputation scale. To ensure that the subjects were similar in the severity of the two types of crisis events, refer to Coombs (1995) and Yan Jun, Qu Qiuling (2010) for the study of the crisis severity scale. In addition, the crisis category consisted of two items: "fault type" and "deliberate type" of the food safety crisis.

The above variables are measured, except that the type of crisis belongs to the identification item, and the 7-level Likert scale is used ("1" means "completely disagree", "7" means "completely agree"), and for English scale items, A double-blind translation method is used to ensure that the title of the item is accurate.

This paper is divided into two stages: pretest and formal experiment. The experiments were conducted in three colleges and universities in Chengdu, and all the subjects were full-time undergraduate students.

In the pre-test phase, the paper is divided into two steps: First, 60 undergraduate students are invited as the sample, and the sample is distributed to the four experimental groups based on the random principle. Secondly, the participants were asked to explain the basic requirements of the questionnaire, and the participants were asked to carefully read the experimental materials held and responded according to the order of the questionnaires. In view of the fact that the experimental 
materials or items in the pre-tested experiments are not easy to understand, the research invites team members to discuss each other and solve them.

The formal experimental phase is consistent with the specific implementation steps of the pre-test phase. In the formal experiment, the study randomly invited 240 full-time undergraduate students from three comprehensive universities in Chengdu to participate in the questionnaire survey. Each experimental group assigned 60 subjects to answer in accordance with the requirements of the experimental questionnaire.

\section{Data analysis}

\subsection{Sample overview}

A total of 240 experimental questionnaires were distributed in this experiment. After eliminating the sample questionnaires in which the crisis category was judged incorrectly, the answers were incomplete, or all the items were selected the same, the valid samples were finally determined, and the effective number of the participants in each experimental group was 45. More than 89 people and 104 women. The subjects in this study were homogenous and the sample size met the experimental requirements. Based on analysis of variance, male and female genders had no significant effect on ability trust and good faith trust (F-capability trust $(1,191)=0.021$, $\mathrm{p}=0.885>0.05$; F-good faith trust $(1,191)=0.014, \mathrm{p}=0.907>0.05)$.

\subsection{Reliability and validity test}

All variables are based on the maturity scale, so the reliability and validity are good. First, in the reliability test, the alpha coefficient of psychological risk is 0.948 , the alpha coefficient of competence trust and good faith trust are 0.957, 0.948, respectively, and the alpha coefficients of brand reputation and crisis severity are 0.906 and 0.939 , respectively. Secondly, in the results of confirmatory factor analysis, the minimum value of the normalized factor load factor of the measurement items of each variable is 0.796 , and the maximum value is 0.893 , which is between 0.5 and 0.95 . The internal structure is well fitted and the average of each variable is average. The extracted variance AVE values ranged from 0.67 to 0.87 , both greater than the critical criterion of 0.5 .

\subsection{Control inspection}

The results of analysis of variance showed that there was no significant difference in brand reputation among the experimental groups $(\mathrm{Mmin}=5.430, \mathrm{M} \max =5.776, \mathrm{~F}(3,189)=1.653, \mathrm{p}=$ 0.179), indicating the homogeneity of corporate brand reputation. Successfully manipulated. There was no significant difference in the degree of perceived severity of the crisis between the experimental groups $(\mathrm{Mmin}=5.250, \mathrm{M} \max =5.521, \mathrm{~F}(3,189)=0.450, \mathrm{p}=0.717)$, indicating that the severe homogeneity of the crisis was successful. Control.

\subsection{Hypothesis testing}

In this paper, the main effect (H1) of the two types of food safety crisis is verified by two-way analysis of variance with the ability trust and good faith as the dependent variables. The results show that the negative impact of the negligent food safety crisis and the deliberate food safety crisis on the ability trust has significant differences $(F(1,191)=9.833, p=0.002)$, thus verifying the deliberate food safety crisis than the negligent food safety crisis. The negative impact on consumer brand trust is large, and $\mathrm{H} 1$ (H1a-H1b) is verified.

Further verify the mediating role of psychological risk (H2 and H3). Taking psychological risk as the independent variable and regression analysis with ability trust and good faith as the dependent variable respectively, the standardized regression coefficient of psychological risk and ability trust is -0.599 , which can explain the variance of $35.6 \%$ of ability trust; psychological risk and good faith trust The standardized regression coefficient is -0.542 , which explains the ability to trust $29.0 \%$ of the variance. From the analysis of variance of the regression equation, the total explanatory variation of the two regression models reached a significant level (F-capability trust 
$(1,191)=107.137, p=0.000<0.05$; F-good faith trust $(1,191)=79.461, p=0.000<0.05)$. The results also show that consumers' psychological risk negatively affects consumers' ability to trust enterprises $(\beta=-0.599, \mathrm{t}=-10.351, \mathrm{p}=0.000<0.05)$ and good faith trust $(\beta=-0.542, \mathrm{t}=-8.914, \mathrm{p}=0.000$ $<0.05$ ), that is, the greater the psychological risk, the more negative the consumer's ability to trust, the greater the psychological risk, the more negative the consumer's good faith trust, $\mathrm{H} 2$ (H2a-H2b) is verified.

Finally, H5 (H5a-H5b) was verified. In this paper, the categorical variables are converted into a corresponding dummy variable by assignment, and the "fault type" in the food safety crisis category is assigned " 0 ", the "deliberate type" is assigned " 1 ", and the independent variable and dependent variable are further Regression analysis of independent variables and mediator variables and the correlation between independent variables, mediator variables and dependent variables. The food safety crisis category has significant explanatory power for psychological risk $(\mathrm{p}=0.036<0.05)$, ability trust $(\mathrm{p}=0.008<0.05)$ and good faith trust $(\mathrm{p}=0.000<0.05)$, and the standardized regression coefficient with psychological risk is 0.151 , which can explain the $1.8 \%$ variation of psychological risk, and the standardized regression coefficient of ability trust is -0.189 , which can explain the $3.1 \%$ variation of ability trust; the standardized regression coefficient with good faith trust is -0.356 , which can explain the ability trust $12.2 \%$ The amount of variation. The psychological risk was taken into the regression equation and the food safety crisis category was selected into the regression equation. The standardized regression coefficient of food safety crisis category and ability trust was changed from -0.189 to -0.101 , and the standardized regression coefficient was not significant $(p=0.085>0.05)$. ), and the regression coefficient of psychological risk is significant $(p=0.000<0.05)$, indicating that psychological risk plays a full mediating role in the process of food safety crisis impact ability trust, while the standardized regression coefficient of food safety crisis category and good faith trust is -0.356 Declining to -0.280 , the standardized regression coefficient is still significant $(\mathrm{p}=0.000<0.05)$, and the regression coefficient of psychological risk is significant $(\mathrm{p}=0.000<0.05)$, indicating that psychological risk plays a part in the process of food safety crisis affecting consumer brand trust. Mediating, H3 (H3a-H3b) was verified.

\section{Conclusions and implications}

\subsection{Research conclusions}

This paper verifies the negative impact of the food safety crisis on consumer brand trust and the mediating role of psychological risk through empirical research, and draws the following specific research conclusions:

First, in contrast to the negligent food safety crisis, deliberate food safety crises often have a greater negative impact on consumer brand trust.

Second, psychological risk plays a mediating role in the process of two types of food safety crisis affecting consumer brand trust. The study found that psychological risk played a full intermediary role in the process of trustworthy and deliberate food safety crisis impact ability, and played a part in mediating the process of affecting good faith trust.

\subsection{Management enlightenment}

The psychological risk in consumer perceived risk cannot be ignored in the relevant strategies for repairing brand trust. Food companies should strive to reduce the psychological risks of consumers by improving product quality and social responsibility in the public relations work of repairing ability trust, ensuring consumers' anxiety and nervousness in the food purchase and consumption process of food enterprises. minimize.

\section{Acknowledgements}

Fund Project: Fund Project: Key Research Base of Philosophy and Social Science of Sichuan Province--Southwestern Poverty Reduction and Development Research Center Key Project (SCP1802); Sichuan Agricultural University Social Science Key Project (2018ZD04); Sichuan 
Province Philosophy and Social Science Key Research Base--Sichuan Agriculture Featured Brand Development and Communication Research Center General Project (CAB1810)

\section{References}

[1] Li Xuemo. The report of "Consumer Consumer Food Safety Trust Research" of Jinan University shows that consumers have a strong need for food quality information [J]. China Food and Drug Administration, 2016(5): 49-50.

[2] Siomkos G J, Kurzbard G. The Hidden Crisis in Product-harm Crisis Management [J]. European Journal of Marketing, 1994, 28(2): 30-41

[3] Fang Zheng, Yang Yang, Li Wei, et al. Study on the occurrence conditions and coping strategies of product injury crisis spillovers_—Predicting and responding to product injury crisis caused by other brands[J]. Nankai Business Note, 2013, 16(6) :19-27.

[4] Coombs W T. Protecting Organization Reputations During a Crisis: The Development and Application of Situational Crisis Communication Theory [J]. Corporate Reputation Review, 2007, 10(3): 163-176.

[5] Zhou Yingheng, Wang Erpeng. China Food Safety Supervision: An Overall Framework [J]. Reform, 2013(4): 19-28.

[6] Yuan Denghua, Luo Yuming, Li You. Research on Brand Trust Structure and Its Measurement[J]. Psychology, 2007, 27(3): 81-86.

[7] Shou Zhigang, Su Chenting, Yang Zhilin, et al. How Retailers' Ability and Friendship Influence Suppliers' Relationship Behavior_—An Empirical Study Based on Trust Theory[J]. Management World, 2008(2): 97-109.

[8] LU Juan, ZHANG Zhenxing, YANG Qingqing. Research on Trust Enhancement of Food Brand Based on Brand Combination[J]. Journal of Business Economics and Management, 2011, 1(1): 76-85.

[9] Duan Guimin, Yu Weiping. Research on the Impact of Sub-brand Injury Crisis on the Evaluation of Main Brands__-Intermediary Role of Consumer Negative Emotions[J]. East China Economic Management, 2012, 26(4): 115-119.

[10]Wang Xiaoyu, Yan Gangling. Influence of word-of-mouth direction on consumer attitude in product crisis[J]. Journal of Marketing Science, 2008(4): 1-12.

[11]Corbitt B J, Thanasankit T, Yi H. Trust and e-commerce: a study of consumer perceptions [J]. Electronic Commerce Research \& Applications, 2003, 2(3):203-215.

[12] Stone R N, Grønhaug K. Perceived risk: Further considerations for the marketing discipline [J]. European Journal of marketing, 1993, 27(3): 39-50.

[13]Cleeren K, Heerde HJV, Marnik, et al. Rising from the Ashes: How Brands and Categories Can Overcome Product-Harm Crises [J]. Journal of Marketing A Quarterly Publication of the American Marketing Association, 2013, 77(2) :58-77.

[14]Dawar N, Lei J. Brand crises: The roles of brand familiarity and crisis relevance in determining the impact on brand evaluations [J]. Journal of Business Research, 2009, 62(4): 509-516.

[15]Fombrun C J, Riel C B M V. The Reputational Landscape [J]. Corporate Reputation Review, 1997, 1(1): 5-13. 